\title{
Foamy Virus Integrase in Development of Viral Vector for Gene Therapy
}

\author{
Jinsun Kim, Ga-Eun Lee, and Cha-Gyun Shin* \\ Department of Systems Biotechnology, Chung-Ang University, Anseong 17546, Republic of Korea
}

\begin{abstract}
Due to the broad host suitability of viral vectors and their high gene delivery capacity, many researchers are focusing on viral vector-mediated gene therapy. Among the retroviruses, foamy viruses have been considered potential gene therapy vectors because of their non-pathogenicity. To date, the prototype foamy virus is the only retrovirus that has a high-resolution structure of intasomes, nucleoprotein complexes formed by integrase, and viral DNA. The integration of viral DNA into the host chromosome is an essential step for viral vector development. This process is mediated by virally encoded integrase, which catalyzes unique chemical reactions. Additionally, recent studies on foamy virus integrase elucidated the catalytic functions of its three distinct domains and their effect on viral pathogenicity. This review focuses on recent advancements in biochemical, structural, and functional studies of foamy virus integrase for gene therapy vector research.
\end{abstract}

Keywords: Foamy virus, integrase, intasome, viral vector

Received: March 24, 2020 Accepted: July 14, 2020

First published online: July 17,2020

*Corresponding author Phone: +82-31-670-3067 Fax: +82-31-675-3108 E-mail: cgshin@cau.ac.kr

pISSN 1017-7825 elSSN 1738-8872

Copyright(C) 2020 by The Korean Society for Microbiology and Biotechnology

\section{Introduction}

Since the concept was established in 1972, gene therapy has been studied in concert with the development of molecular biotechnology [1-3]. The first successful trial of gene therapy in humans was performed in 1989 [4]. In that protocol, patients with melanoma were treated with a gene-modified, tumor-infiltrating lymphocyte construct modified by retroviral transduction. There were no side effects from 3 weeks to 2 months during the monitoring period. In 2017, the FDA approved the first gene therapy in the USA. This novel, genetically engineered chimeric antigen receptor T-cell therapy was soon followed by approval of RPE65 mutation-induced blindness gene therapy. In approximately the last three decades, viral vectors have been used for over 3,000 clinical tasks, from therapy to regenerative medicine, following more than half of them in phase I [5]. Gene therapy has broad prospects as an effective therapeutic strategy for various diseases, including cancer, as well as monogenic, infectious, cardiovascular, and neurological diseases. In terms of types of viruses, adenoviruses, retroviruses, and lentiviruses have been intensively studied, and adeno-associated virus research began recently [5]. However, viral gene therapy vectors pose safety issues, including direct toxicity and stimulation of the immune response [6-8]. Nevertheless, viral vectors have been extensively studied because of their advantages, such as their broad host range, including humans, and high gene transfer rates to host cells.

Among them, the Retroviridae family is composed of two virus subfamilies, six genera of Orthoretrovirinae and four genera of Spumaretrovirinae (commonly called spumaviruses or foamy viruses [FVs]). FVs were first mentioned as a contaminant in primary monkey kidney cultures in 1954 [9]. Since 'foamy viral agent' was first isolated in 1955, FV has been found in various mammalians, including humans [10]. FVs are exogenous viruses that induce the specific cytopathic effect (CPE), or 'foamy' appearance in host cells [11]. The FV life cycle is different from other retroviruses. First, FV buds from the endoplasmic reticulum instead of the cytoplasmic membrane. This helps form the FV's unique 'spike surface' morphology [11]. Furthermore, the replication of FV is like that of Hepadnaviridae, which is another family of virus that has reverse transcriptase-encoding gene. Reverse transcription of FV genome occurs not in the early steps like other retroviruses, but also in the late steps of replication [12]. Although FV-infected cells show characteristic large vacuoles in vitro, there have been no reported serial diseases from FV infection in vivo, so FVs have been considered potential gene therapy vectors [10]. Here, we discuss research achievements with foamy virus vectors (FVVs) in gene therapy and specifically focus on the characteristics of FV integrase (IN) and its prospective functions associated with vector research.

\section{FVs as Viral Vector Candidates}

FVs have a broad range of tissue and cell tropism, and virus infections are generally latent, except in some tissues of the oral cavity. It is highly prevalent in diverse non-primate mammalian animals such as cows, horses, cats, and bats [10]. Interspecies transmission of FVs to humans by exposure to tissue fluids from infected non-human primates has been reported [13, 14]. Unlike other retroviral vector systems, FVV systems do not rely on virusencoded encapsidation sequences for the transfer of heterologous genetic material, thus enabling the efficient 
transient expression of FVV [15]. In the last decade, many studies have demonstrated the efficacy of FVV in curing monogenetic diseases of hematopoietic origin in humans, non-human primates, canines, and rodents [1620]. In vivo FVV-based gene therapy approaches have been established in the X-linked severe combined immunodeficiency canine model $[17,18]$. FVV is also capable of infecting hematopoietic stem progenitor cells [20]. Most recently, it was shown that intramuscular transplantation of FVV-transduced Duchenne muscular dystrophy myoblasts could restore dystrophin for individual small muscles in mice [21].

\section{Basic Biochemistry of FV IN}

Retroviruses are the only viruses that require the integration of genetic information into the host genome as a necessary step for replication [1]. All species of the Retroviridae family carry with them an IN, which is a specialized DNA recombination enzyme [22]. Recombinant prototype foamy virus (PFV) IN affords assembly of all key intermediates of retroviral integration, presenting unprecedented experimental approaches to probe interactions between the viral machinery and its cellular partners [23]. Furthermore, PFV IN is a model enzyme for studying the mechanism of retroviral integration. Compared with IN from other retroviruses, PFV IN is highly soluble and more amenable to experimental manipulation [24]. Furthermore, it is sensitive to clinically relevant human immunodeficiency virus (HIV) IN inhibitor, indicating that PFV IN can be used for HIV-1 integrase strand transfer inhibitor (INSTI) screening [25].

Integration is an essential step for the efficient expression of viral genes by the host transcriptional machinery and, hence, it is also crucial for productive virus replication [22]. Integration occurs within the context of an intasome, which consists of a multimerized IN engaging the two viral DNA (vDNA) ends [26]. The first reaction of retroviral integration is 3 '-end processing. In this process, IN removes the terminal dinucleotides following the conserved CA sequence at the $3^{\prime}$-ends of the long terminal repeat (LTR). Secondly, the strand transfer is a phosphoryl transfer reaction in which the 3'-hydroxyl ends of the vDNA donate an electron pair as the nucleophile, resulting in covalent joining between vDNA and target DNA (tDNA) $[27,28]$. Disintegration, an additional reaction that occurs in vitro only, is the reverse process of strand transfer in which the inserted vDNA cleaves off from the tDNA [29] (Fig. 1).

Retroviral IN proteins comprise three or four functional domains. The $\mathrm{N}$-terminal domain (NTD), the catalytic core domain (CCD), and the C-terminal domain (CTD) are common to all of the IN proteins [30, 31]. The NTD contains a characteristic zinc-binding HHCC motif, and the CCD harbors a highly conserved acidic triad Asp, Asp $_{35}$, and Glu, known as the $\mathrm{D}, \mathrm{D}_{35}$, and $\mathrm{E}$ motif, which is essential for the catalysis of 3 '-end processing, strand transfer, and disintegration [32]. The INs from the spuma-, epsilon-, and gamma-retroviruses additionally carry the NTD extension domain involved in interactions with vDNA.

The retroviral integration step is accomplished by 3 '-end processing and strand transfer steps, which are bimolecular nucleophilic substitution $\left(\mathrm{S}_{\mathrm{N}}{ }^{2}\right)$ reactions [33-37]. Most retroviral INs remove the terminal dinucleotides (GT in HIV-1, TT in avian sarcoma leukosis virus) from each 3'-end of the vDNA during the 3'-end processing $[35,37]$. However, interestingly, FV integration does not require the removal of two terminal nucleotides from its U3 region. In contrast, a terminal dinucleotide (AT) is removed from only its U5 region to provide the subterminal CA sequence for the joining reaction to the host chromosome [36]. In the strand transfer reaction, FV IN employs the free 3'-hydroxyl of the vDNA to attack the tDNA. The subsequent eliminations of the unpaired dinucleotide at each 5'-overhanging end of the vDNA and the filling of the gaps are most likely performed by host enzymes [37]. In terms of structural and mechanistic similarities, retroviral INs belong to a metal-dependent nucleotidyltransferase family. The active sites of these enzymes contain essential acidic residues that participate in coordination with a pair of $\mathrm{Mg}^{2+}$ or $\mathrm{Mn}^{2+}$ cations [38].

To investigate enzyme catalytic activities and interactions with tDNA in vitro, recombinant IN purification, followed by bacterial expression and integration assays, have been generally used. For enzyme purification from bacterial expression systems, a hexahistidine tag is commonly included in IN expression constructs for initial purification with a nickel resin [24,39-41]. Recombinant IN is commonly fractionated by heparin-Sepharose affinity chromatography with a salt gradient, followed by nickel chromatography for bacterial nuclease-free IN purification. Purified FV INs can perform three types of in vitro enzymatic activities: 3 '-end processing, strand

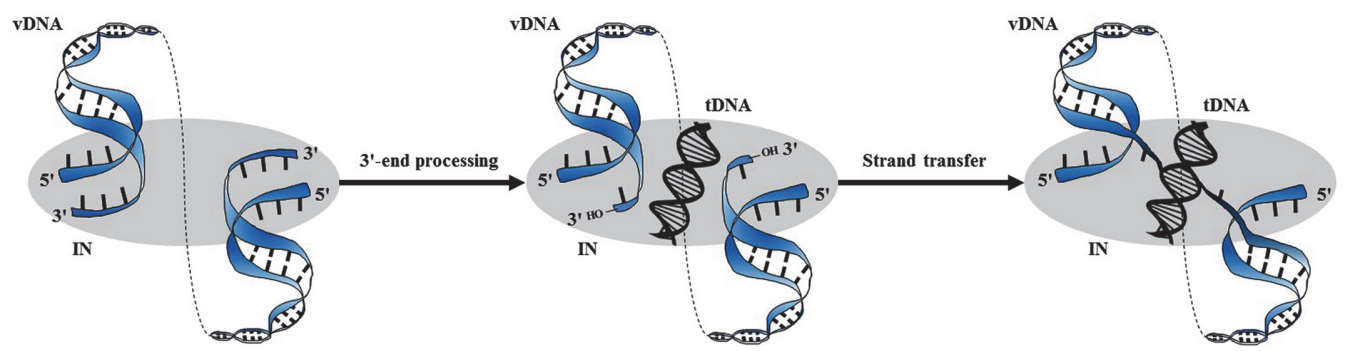

Fig. 1. IN catalytic functions and intasome complexes. A multimer of IN (depicted simply by the gray oval) engages the end regions of the linear vDNA molecule (blue), forming a stable synaptic complex. During 3'end processing, IN hydrolyzes the vDNA ends adjacent to the invariant CA dinucleotides, revealing a set of reactive 3'-hydroxyl groups in the cleaved donor complex. In the strand transfer step, IN employs the 3'-hydroxyl groups as nucleophiles to attack tDNA. 
transfer, and disintegration [42]. Among them, 3 '-end processing and the strand transfer step require specific DNA substrates and intact IN proteins. Furthermore, it has been shown that the IN CCD plays an important role in binding vDNA, and also, in target site selection [43].

Two functional domains engage in metal binding for retroviral integration $[38,39]$. One of them is the NTD, which includes a zinc finger motif that binds $\mathrm{Zn}^{2+}$. The second domain, the CCD, contains a conserved $\mathrm{D}, \mathrm{D}_{35}$, and E motif and has been known to bind divalent metal cofactors, such as $\mathrm{Mn}^{2+}$ and $\mathrm{Mg}^{2+}$. FV IN has low substrate specificity compared with HIV IN. Moreover, the substrate usage of IN is different among FV INs. Specifically, feline foamy virus (FFV) IN has a broader range of substrates than PFV IN. $\mathrm{Mn}^{2+}$ or $\mathrm{Mg}^{2+}$ metal ions are known as required cofactors of retroviral IN activities. $\mathrm{Mg}^{2+}$ is a natural cofactor because of its abundance in vivo, but retroviral IN activities, as well as FV IN in vitro activities, are most efficient in the presence of $\mathrm{Mn}^{2+}[42,44]$. Some in vitro integration assay studies reported that other transient elements could work as cofactors when FV IN adapts them in the metal-binding sites [44]. According to the results, $\mathrm{Co}^{2+}$ and $\mathrm{Zn}^{2+}$ ions were found to act in the three kinds of enzymatic activities of FFV IN in the absence of $\mathrm{Mn}^{2+}$ ions in vitro, and their inductions of enzymatic reactions were concentration dependent.

FV IN has higher solubility, faster kinetic properties, and a broad range of substrates compared with other retroviruses. These biochemical properties of FV IN facilitate studies of retroviral integration [45].

\section{Structural Analysis of FV Integration}

Numerous biochemical studies have revealed that the active form of retroviral IN is a multimer that engages vDNA and tDNA in the confines of a nucleoprotein complex [46-54]. Bacteriophage Mu-mediated PCR of preintegration complexes (PICs) extracted from infected cells revealed the protection of several hundred base pairs at the vDNA ends, and the associated complex was termed an "intasome" to distinguish it from the larger PICs [55, 56]. The number of IN monomers per intasome may be four, eight, or possibly higher-order multimers [57]. PFV IN was the first full-length IN protein to be crystallized with vDNAs and tDNAs [58,59]. Additionally, among the retroviral INs, only PFV IN has yielded diffractable intasome crystals [28, 44].

In 2010, the crystal structure of the 3'-end-processed PFV synaptic complex provided the first observation of any retroviral intasome [59]. Today, the PFV intasome can be considered a minimalist assembly with the lowestorder IN-to-vDNA stoichiometry among the retroviral intasomes already characterized [60]. The PFV intasome is a two-fold symmetric complex harboring four IN subunits, with vDNA ends synapsed between a pair of IN dimers [59](Fig. 2A). The inner IN molecules of each dimer are responsible for all interactions with vDNA and provide their active sites to catalyze the integration reactions. The inner subunits interact with each other across the synaptic interface, and an underlying theme of the intasome is the swapping of the inner NTDs to function in trans with the opposing CCDs. The associated CTDs engage tDNA during integration and help to rigidly bridge the halves of the intasome together [58, 61] (Fig. 2B). Depending on the retroviral genus, vDNA insertion points are spaced four to six base pairs apart in the host DNA [62]. The differences in size, sequence, and charge distribution among the inner CTDs suggest that each one forms a unique intasome structure, which results in unique spacing between the vDNA insertion position in the tDNA. The outer IN subunits attach to the catalytic inner molecules via the CCD-CCD dimerization interface [37].

Solution-based measures indicated that tetrameric IN forms could be the functionally relevant multimers for the integration of alpha-retroviral [50,63] and lentiviral DNA [46, 47, 49, 64]. Although arguments and experimental evidence for comparatively larger species were also presented $[46,65,66]$, the homo-tetrameric architecture observed in the PFV intasome was expected to be a universal feature of the retroviral integration machinery [66]. However, recent intasome structures from other orthoretroviruses revealed both striking

A

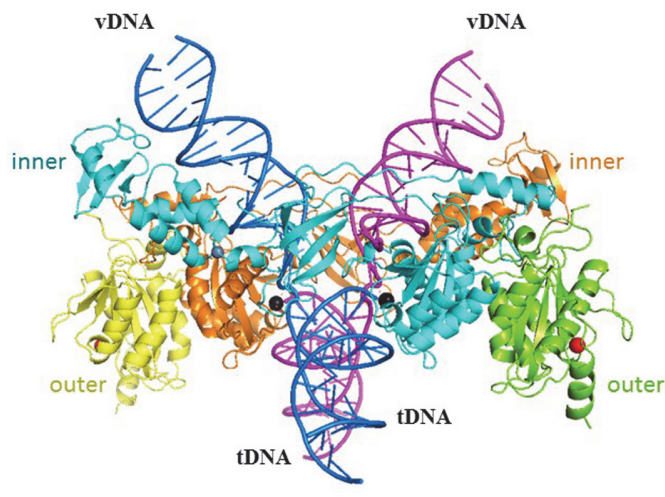

B

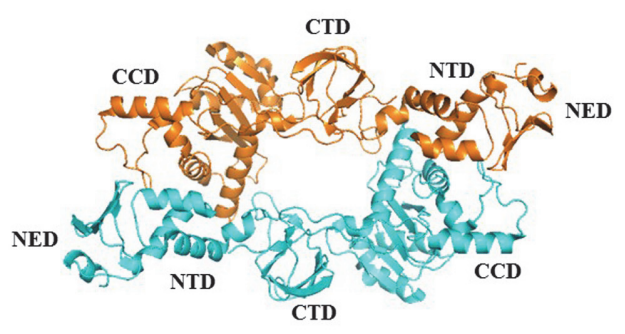

Fig. 2. Structure of PFV IN-product complex. PDB ID 3L2R and 3052 were used for creating a rigid body. (A) Orthogonal view of tetrameric PFV IN in complex with two vDNA ends inserted into a tDNA. The two inner subunits are shown in cyan and orange, and the two outer subunits are shown in green and yellow. The two DNA molecules are shown in blue and magenta, each consisting of one vDNA end and half of the tDNA. (B) Ribbon diagram of two inner subunits of PFV IN intasome. 
complexity and diversity. Whereas the PFV intasome is constructed from four IN molecules, the mouse mammary tumor virus and Rous sarcoma virus structures contain eight IN molecules, assembled as tetramers of dimers. As in the PFV intasome, the catalytic subunits exchange their NTDs across the synaptic interface [47, 57]. The intasome is completed by insertion of CTDs, in this case, from the flanking IN dimers [26]. Collectively, the recent structural studies cited above highlight remarkable evolutionary flexibility in the construction of the intasome. Although, in principle, a functional intasome could be composed of only two catalytic IN subunits, the smallest complex observed to date is a tetrameric PFV intasome [66]. Interestingly, the NTD extension domain, NTD, and CTD of the outer IN subunits are dispensable for catalytic reactions in vitro $[32,58,59,67,68]$. However, the outer IN subunits were implicated in interactions with nucleosomal DNA during integration into chromatinized targets [23].

Retroviral integration may be modeled in vitro with recombinant retroviral IN and DNA oligomers mimicking the ends of the viral genome. However, they are not ideal reagents for the study of the dynamics or structure of integration complexes when monomeric IN would obscure relevant visualization. Purified intasomes are required for dynamic single-molecule analysis or structural studies. Consequently, integration assays may test the effects of IN mutations, IN inhibitors, or other chemical additives. Mackler et al. proposed optimal conditions for the assembly and purification of PFV intasomes [69].

Retroviral DNA is not randomly inserted into a host chromosome. Its genus-specific biases at the level of local tDNA sequences and chromatin features have been reported [70-73]. HIV-1 and some species of lentivirus favor integration within active transcription regions [74], whereas Moloney murine leukemia virus (MLV), a gammaretrovirus, preferentially integrates into the vicinity of transcription start sites and CpG islands [75-79]. Less distinctive patterns have been observed for FVs; PFV somewhat disfavors integration within transcription regions, regardless of local gene expression activity [80,81]. Analyses of retroviral integration sites have revealed weak palindromic tDNA sequence consensuses at the sites of vDNA joining [71, 73, 82-84]. A palindromic consensus implies paired symmetry within the intasome that engages the tDNA. The crystallographic analysis of PFV revealed key features of the inner IN dimer (within the tetramer) that dictate the selection of the consensus PFV integration site $(-3) \mathrm{KWK} \backslash V Y R B M W M(+6)$ (the italics mark the target site duplication of four base pairs flanking the PFV provirus, and the backslash indicates the position of vDNA joining) [36, 58].

Inhibitors of HIV-1 that target IN recognize the retroviral intasomes rather than the free enzyme [68]. Atomic resolution structures of other retroviral intasomes are therefore required to understand the mechanisms of inhibition and drug resistance.

\section{Genomic Analysis of FV IN DNA}

The INs from FV are composed of four functionally distinct domains joined via highly divergent flexible linkers. Functional studies of these domains have been performed using IN point mutations, deletion mutations, and domain-swapping chimeric INs $[42-44,52,53,85,86]$. In vitro enzyme activities of PFV IN cannot be separated into independent domains. In one study, the PFV NTD deletion $(\Delta 1-34)$ mutant lost DNA strand transfer activity but had detectable 3 '-end processing (13\%) and disintegration (33\%) activity in vitro [87]. These reduced activities of the NTD deletion mutant indicate that full catalytic activity (strand transfer, 3'-end processing, and disintegration) requires the HHCC motif but also the upstream sequences of this domain. The chimeric INs with the CCD of PFV IN or HIV IN did not have any enzymatic activities due to the differences in vDNA recognition between PFV CCD and HIV CCD [42]. Such results show that the central domain of PFV IN alone is not able to recognize vDNA without help from the NTD and CTD [42]. Sequence alignment of the CCD active site of FFV IN with HIV-1 revealed that residues D107, D164, Q165, Y191, S195, and E200 affects the in vitro catalytic reactions, viral replication, and viral infectivity [43]. The single residue mutations in the active sites of FFV IN remarkably decreased the efficiency of the three IN enzymatic activities, viral replication, and viral infectivity. Additionally, the amino acid substitution of the FFV IN C-terminal residues R307 and K340 to glutamic acid dramatically affected the enzymatic activities of the protein in vitro and noticeably reduced viral production in the infected cells [86]. Such findings indicate that mutations in the CCD of FV IN might lead to improper conformational changes in the complex of the enzyme and DNA substrate.

Viral cDNA is synthesized in the cytoplasm, and this is associated with other cellular and viral proteins to form a PIC. The PIC must be transported to the nucleus, as the retroviral integration occurs within the nucleus. Various cellular nuclear-import receptors are pivotal in translocating PIC to the nucleus. Among the cellular nuclearimport receptors, the involvement of the importin a/ß heterodimer, importin 7 , and transportin 3 (TNPO3) has been extensively studied [88-90]. Some studies using a monoclonal antibody targeted to FV IN suggested that Pol and Gag proteins translocate to the nucleus [88] and facilitate integration by tethering the vDNA to the host chromosome [89]. A separate study suggested that translocation of the viral genome to the nucleus is entirely dependent on IN [90]. It has also been shown that the FV genome, as well as Gag proteins, can access the nuclei of growth-arrested cells, indicating that like lentiviruses, the FV PIC can also translocate across an intact nuclear membrane. Nevertheless, cells transduced with IN-deficient vectors reveal no Gag proteins within the nuclei, suggesting that the Gag protein alone is insufficient for PIC translocation to the nucleus and that IN is an absolute requirement in growth-arrested cells [91]. Members of the retroviral family possess nuclear localization signals at different IN residues [92]. PFV IN possesses a potent nuclear localization signal in its CTD spanning residues 289-371; an amino acid mutation study revealed that some residue positions (308, 313, 318, 324, and 329) notably affect nuclear localization [93]. TNPO3 is a karyopherin involved in transporting phosphorylated serine/ arginine-rich proteins between the cytoplasm and nucleus, and it is known to be a key factor involved in HIV-1 replication $[94,95]$. In one study, TNPO3 knockdown reduced PFV production in BHK-21 cells and human 293T 
cells [94]. Furthermore, the interaction of TNPO3 with PFV IN was reduced, underscoring that IN-TNPO3 interactions are critical for the nuclear import of PFV PIC through the nuclear pore complex [95].

FVs are complex retroviruses that regulate their gene expression by unique features: a spliced pol transcript and an internal promoter directing the expression of the APOBEC-antagonizing protein Bet and the viral transactivator [96-100]. FV synthesizes Pol independently of Gag. The FV Pol precursor is cleaved only once between reverse transcriptase and IN by a protease (PR), resulting in a PR/reverse transcriptase and an IN protein [97, 98, 101]. The FV genome encodes four central purine-rich elements (A, B, C, and D), which are localized within the $\mathrm{IN}$-encoding region [102]. The $\mathrm{A}$ and $\mathrm{B}$ elements are essential for $\mathrm{PR}$ dimerization and activation, the $\mathrm{C}$ elements are required for Gag expression [102, 103], and the D elements act as a polypurine tract during reverse transcription [104]. Pol mutants lacking IN have defects in PR activity and Pol packaging into virions. When PR is part of Pol, Pol can form dimers because of IN-IN interactions [105]. However, recently, contradictory results on FV PR activity were published. One study suggested that IN is involved in the regulation of PR [106]. This study proposed that FV IN is required for Pol encapsidation and that PR activity is regulated by viral RNA, not IN.

\section{Prospective Functions of FV IN}

FV INs are highly appropriate for structural studies of the retroviral synaptic complex. Recombinant PFV IN is capable of executing 3 '-end processing, half-site strand transfer, and concerted integration in vitro under stringent conditions $[87,107]$. In the case of PFV IN, it is capable of utilizing preprocessed oligonucleotide donor DNA as short as 16 base pairs to carry out concerted strand transfer, almost exclusively [24]. However, HIV-1 IN requires DNA molecules with several hundred base pairs and additional substances, such as dimethyl sulfoxide/ polyethylene glycol, for concerted integration $[108,109]$. Moreover, PFV IN forms much stronger complexes with synthetic DNA duplexes that mimic the terminal sequences of the vDNA long terminal repeat U5 domains, much faster than DNA association with HIV IN (approximately five-fold faster) [110-113].

Structural studies of FV IN-DNA complexes have provided a breakthrough for understanding the mechanisms of retroviral integration site selection $[58,59]$. Each retrovirus genus shows a unique insertion pattern, which is regulated by cellular and viral factors, as well as by the local DNA conformation and chromatin structure at the site of integration. An improved understanding of the integration site selection process has recently emerged with the advent of next-generation sequencing methods to identify insertion sites [59], the resolution of the architecture of the PFV integration machinery [114], and the cellular cofactors involved in the process [115]. Aiyer et al. investigated the MLV IN domain structure to identify tDNA binding residues, the CCD $\alpha 2$ helical region, and the CTD $\beta 1-\beta 2$ loop [114]. The results showed that the MLV IN CCD is highly assisted by the PFV intasome and that the MLV IN CTD interchanges with PFV IN CTD. These findings indicated that FV INs are promiscuous for species-specific retroviral integration site selection and IN functional studies for HIV-1 integrase strand transfer inhibitors in terms of their target commitment, higher solubility, faster kinetic properties, and a broad range of substrates compared with HIV IN [28, 44].

Vector systems based on different retroviruses are widely used to achieve stable integration and expression of transgenes due to vector-genome integration into host cell chromosomes. Transient genetic manipulation systems that are based on integration- or reverse transcription-deficient gamma-retroviral vectors bear the risk of detrimental mutagenesis, which became apparent in several clinical trials in which vector genome integration led to oncogene activation [116]. FVV systems provide a useful and novel tool for the efficient transient genetic manipulation of target tissues by the stable delivery of non-viral nucleic acids. Self-inactivating, clinically-relevant FVV systems [117-120] have been developed for gene therapy in large animal models and proven effective [121, 122]. By using IN modification or hybrid systems with other proteins, it is possible to alter the integration profile of FVs, reducing the frequency of retroviral vector integration sites [123]. Deyle et al. generated non-integrating FVVs by introducing point mutations into active sites of the FV IN CCD sequence and demonstrated that cells infected with non-integrating FVVs expressed transgenes and became progressively diluted in the dividing cell population [124]. FVs are the most promising vectors for large transgene delivery because they have the largest mammalian retroviral genome $[117,125,126]$. Sweeney et al. investigated the ability of FVVs to incorporate the simian macaque FV envelope using physiological promoters to efficiently deliver large transgene cassettes by inserting increasing lengths of the dystrophin open reading frames in an FVV before quantifying the packaged vector RNA and integrated DNA [127, 128]. Molecular assays showed that a 12-kb insert could be packaged, delivered, and integrated into a target human cell genome at a sufficient titer for ex vivo gene therapy. This approach allows greatly exceeding the maximum insert size of lentivirus vectors of approximately $7 \mathrm{~kb}$, making FVV an excellent candidate for the stable and efficient transfer of large transgenes.

Besides Spumavirus, four other genera have now been identified in the Spumaretrovirinae subfamily (Prosimiispumavirus, Bovispumavirus, Felispumavirus, and Equispumavirus), justifying the recent increase in the number of studies on FVs. FV INs have many advantages for the study of the structural and catalytic properties of retroviral INs. FV IN has a similar sensitivity to HIV-1 inhibitors, and the crystal structure of the PFV intasome, as the only determined retroviral intasome to date, will help to investigate and develop novel HIV-1 INSTIs. This review should provide insights into the biochemical activities and structural and genomic properties of FV INs. It also presents the reasons for using FV IN as a surrogate model to study the structural basis of anti-retroviral therapy, as well as to improve the safety and efficiency of FVV systems. 


\section{Acknowledgments}

This study was supported by a grant from the National Research Foundation (NRF) of Korea, funded by the Korean government (NRF-2018R1D1A1A09081872).

\section{Conflict of Interest}

The authors have no financial conflicts of interest to declare.

\section{References}

1. Busch H, Choi YC, Crooke ST, Okada S. 1972. Genetic engineering and cancer chemotherapy. Oncology 26: 152-179.

2. Goff SP, Berg P. 1976. Construction of hybrid viruses containing SV40 and l phage DNA segments and their propagation in cultured monkey cells. Cell 9: 695-705

3. Cepko CL, Roberts BE, Mulligan RC. 1984. Construction and applications of a highly transmissible murine retrovirus shuttle vector. Cell 37: 1053-1062.

4. Rosenberg SA, Aebersold P, Cornetta K, Kasid A, Morgan RA, Moen R, et al. 1990. Gene transfer into humans-immunotherapy of patients with advanced melanoma, using tumor-infiltrating lymphocytes modified by retroviral gene transduction. N. Engl. J. Med. 323: $570-578$.

5. The Journal of Gene Medicine. 2019. Gene Therapy Clinical Trials Worldwide Database. Available from https://www.abedia.com/ wiley/index.html. Accessed Mar. 10, 2020.

6. Baum C, Düllmann J, Li Z, Fehse B, Meyer J, Williams DA, et al. 2003. Side effects of retroviral gene transfer into hematopoietic stem cells. Blood 101: 2099-2114.

7. Raper SE, Chirmule N, Lee FS, Wivel NA, Bagg A, Gao GP, et al. 2003. Fatal systemic inflammatory response syndrome in an ornithine transcarbamylase deficient patient following adenoviral gene transfer. Mol. Genet. Metab. 80: 148-158.

8. Hidai C, Kitano H. 2018. Nonviral gene therapy for cancer: a review. Diseases 6: 57.

9. Enders JF, Peebles TC. 1954. Propagation in tissue cultures of cytopathogenic agents from patients with measles. Proc. Soc. Exp. Biol. Med. 86: 277-286

10. Lindemann D, Rethwilm A, 2011. Foamy virus biology and its application for vector development. Viruses 3: 561-585.

11. Meiering CD, Linial ML. 2001. Historical perspective of foamy virus epidemiology and infection. Clin. Microbiol. Rev. 14:165-176.

12. Moebes A, Enssle J, Bieniasz PD, Heinkelein M, Lindemann D, Bocket M, et al. 1997. Human foamy virus reverse transcription that occurs late in the viral replication cycle. J. Virol. 71: 7305-7311.

13. Khan AS, Bodem J, Buseyne F, Gessain A, Johnson W, Kuhn JH, et al. 2018. Spumaretroviruses: updated taxonomy and nomenclature. Virology 516: 158-164.

14. King AMQ, Lefkowitz EJ, Mushegian AR, Adams MJ, Dutilh BE, Gorbalenya AE, et al. 2018. Changes to taxonomy and the international code of virus classification and nomenclature ratified by the International Committee on Taxonomy of Viruses (2018). Arch. Virol. 163: 2601-2631.

15. Hamann MV, Stanke N, Müllers E, Stirnnagel K, Hütter S, Artegiani, B, et al. 2014. Efficient transient genetic manipulation in vitro and in vivo by prototype foamy virus-mediated nonviral RNA transfer. Mol. Ther. 22: 1460-1471.

16. Burtner CR, Beard BC, Kennedy DR, Wohlfahrt ME, Adair JE, Trobridge GD, et al. 2014. Intravenous injection of a foamy virus vector to correct canine SCID-X1. Blood 123: 3578-3584.

17. Humbert O, Chan F, Rajawat YS, Torgerson TR, Burtner CR, Hubbard NW, et al. 2018. Rapid immune reconstitution of SCID-X1 canines after G-CSF/AMD3100 mobilization and in vivo gene therapy. Blood Adv. 2: 987-999.

18. Rajawat YS, Humbert O, Kiem HP. 2019. In-vivo gene therapy with foamy virus vectors. Viruses 11: 1091.

19. Trobridge GD, Horn PA, Beard BC, Kiem HP. 2012. Large animal models for foamy virus vector gene therapy. Viruses 4: $3572-3588$.

20. Vassilopoulos G, Trobridge G, Josephson NC, Russell DW. 2001. Gene transfer into murine hematopoietic stem cells with helper-free foamy virus vectors. Blood 98: 604-609.

21. Meng J, Sweeney NP, Doreste B, Muntoni F, McClure M, Morgan J. 2020. Restoration of functional full-length dystrophin after intramuscular transplantation of foamy virus-transduced myoblasts. Hum. Gene. Ther. 31: 241-252.

22. Engelman A, Cherepanov P. 2014. Retroviral integrase structure and DNA recombination mechanism. Microbiol. Spectr. 2: 1-22.

23. Maskell DP, Renault L, Serrao E, Lesbats P, Matadeen R, Hare S, et al. 2015. Structural basis for retroviral integration into nucleosomes. Nature 523: 366-369.

24. Valkov E, Gupta SS, Hare S, Helander A, Roversi P, McClure M, et al. 2009. Functional and structural characterization of the integrase from the prototype foamy virus. Nucleic Acids Res. 37: 243-255.

25. Lopez Jr MA, Mackler RM, Altman MP, Yoder KE. 2017. Detection and removal of nuclease contamination during purification of recombinant prototype foamy virus integrase. J. Vis. Exp. 130: e56605.

26. Engelman AN, Cherepanov P. 2017. Retroviral intasomes arising. Curr. Opin. Struct. Biol. 47: 23-29.

27. Ciuffi A, Bushman FD. 2006. Retroviral DNA integration: HIV and the role of LEDGF/p75. Trends Genet. 22: 388-395.

28. Delelis O, Carayon K, Guiot E, Leh H, Tauc P, Brochon JC, et al. 2008. Insight into the integrase-DNA recognition mechanism: a specific DNA-binding mode revealed by an enzymatically labeled integrase. J. Biol. Chem. 283: 27838-27849.

29. Chow SA, Vincent KA, Ellison V, Brown PO. 1992. Reversal of integration and DNA splicing mediated by integrase of human immunodeficiency virus. Science 255: 723-726.

30. Kulkosky J, Jones KS, Katz RA, Mack JP, Skalka AM. 1992. Residues critical for retroviral integrative recombination in a region that is highly conserved among retroviral/retrotransposon integrases and bacterial insertion sequence transposases. Mol. Cell. Biol. 12: 2331-2338

31. Drelich M, Wilhelm R, Mous J. 1992. Identification of amino acid residues critical for endonuclease and integration activities of HIV1 IN protein in vitro. Virology 188: 459-468.

32. Li M, Lin S, Craigie R. 2016. Outer domains of integrase within retroviral intasomes are dispensible for catalysis of DNA integration. Protein Sci. 25: 472-478.

33. Engelman A, Mizuuchi K, Craigie R. 1991. HIV-1 DNA integration: mechanism of viral DNA cleavage and DNA strand transfer. Cell 67: 1211-1221.

34. Davies DR, Goryshin IY, Reznikoff WS, Rayment I. 2000. Three-dimensional structure of the Tn5 synaptic complex transposition intermediate. Science 289: 77-85.

35. Nowotny M. 2009. Retroviral integrase superfamily: the structural perspective. EMBO Rep. 10: 144-151.

36. Enssle J, Moebes A, Heinkelein M, Panhuysen M, Mauser B, Schweizer M, et al. 1999. An active foamy virus integrase is required for virus replication. J. Gen. Virol. 80: 1445-1452.

37. Dyda F, Hickman AB, Jenkins TM, Engelman A, Craigie R, Davies DR. 1994. Crystal structure of the catalytic domain of HIV-1 integrase: similarity to other polynucleotidyl transferases. Science 266: 1981-1986. 
38. Yang W, Lee JY, Nowotny M. 2006. Making and breaking nucleic acids: two- $\mathrm{Mg}^{2+}$-ion catalysis and substrate specificity. Mol. Cell 22: 5-13.

39. Cherepanov P, Surratt D, Toelen J, Pluymers W, Griffith J, De Clercq E, et al. 1999. Activity of recombinant HIV-1 integrase on miniHIV DNA. Nucleic Acids Res. 27: 2202-2210.

40. Villanueva RA, Jonsson CB, Jones J, Georgiadis MM, Roth MJ. 2003. Differential multimerization of Moloney murine leukemia virus integrase purified under nondenaturing conditions. Virology 316: 146-160.

41. Lopez Jr MA, Mackler RM, Yoder KE. 2016. Removal of nuclease contamination during purification of recombinant prototype foamy virus integrase. J. Virol. Methods 235: 134-138.

42. Yoo GW, Shin CG. 2013. Biochemical characteristics of functional domains using feline foamy virus integrase mutants. BMB Rep. 46: 53-58.

43. Lee GE, Kim J, Shin CG. 2019. Single residue mutation in integrase catalytic core domain affects feline foamy viral DNA integration. Biosci. Biotechnol. Biochem. 83: 270-280.

44. Lee D, Hyun U, Kim JY, Shin CG. 2010. Characterization of biochemical properties of feline foamy virus integrase. J. Microbiol. Biotechnol. 20: 968-973.

45. Ballandras-Colas A, Naraharisetty H, Li X, Serrao E, Engelman A. 2013. Biochemical characterization of novel retroviral integrase proteins. PLoS One 8: e76638.

46. Bera S, Pandey KK, Vora AC, Grandgenett DP. 2009. Molecular interactions between HIV-1 integrase and the two viral DNA ends within the synaptic complex that mediates concerted integration. J. Mol. Biol. 389: 183-198.

47. Li M, Mizuuchi M, Burke Jr TR, Craigie R. 2006. Retroviral DNA integration: reaction pathway and critical intermediates. $E M B O J$. 25: $1295-1304$.

48. Guiot E, Carayon K, Delelis O, Simon F, Tauc P, Zubin E, et al. 2006. Relationship between the oligomeric status of HIV-1 integrase on DNA and enzymatic activity. J. Biol. Chem. 281: 22707-22719.

49. Faure A, Calmels C, Desjobert C, Castroviejo M, Caumont-Sarcos A, Tarrago-Litvak L, et al. 2005. HIV-1 integrase crosslinked oligomers are active in vitro. Nucleic Acids Res. 33: 977-986.

50. Bao KK, Wang H, Miller JK, Erie DA, Skalka AM, Wong I. 2003. Functional oligomeric state of avian sarcoma virus integrase. J. Biol. Chem. 278: 1323-1327.

51. Jonsson CB, Donzella GA, Gaucan E, Smith CM, Roth MJ. 1996. Functional domains of Moloney murine leukemia virus integrase defined by mutation and complementation analysis. J. Virol. 70: 4585-4597.

52. van Gent DC, Vink C, Groeneger AA, Plasterk RH. 1993. Complementation between HIV integrase proteins mutated in different domains. EMBO J. 12: 3261-3267.

53. Engelman A, Bushman FD, Craigie R. 1993. Identification of discrete functional domains of HIV-1 integrase and their organization within an active multimeric complex. EMBO J. 12: 3269-3275.

54. Jones KS, Coleman J, Merkel GW, Laue TM, Skalka AM. 1992. Retroviral integrase functions as a multimer and can turn over catalytically. J. Biol. Chem. 267: 16037-16040.

55. Wei SQ, Mizuuchi K, Craigie R. 1997. A large nucleoprotein assembly at the ends of the viral DNA mediates retroviral DNA integration. $E M B O$ J. 16: 7511-7520.

56. Chen H, Wei SQ, Engelman A. 1999. Multiple integrase functions are required to form the native structure of the human immunodeficiency virus type I intasome. J. Biol. Chem. 274: 17358-17364.

57. Grawenhoff J, Engelman AN. 2017. Retroviral integrase protein and intasome nucleoprotein complex structures. World J. Biol. Chem. 8: $32-44$.

58. Maertens GN, Hare S, Cherepanov P. 2010. The mechanism of retroviral integration from X-ray structures of its key intermediates. Nature 468: 326-329.

59. Hare S, Gupta SS, Valkov E, Engelman A, Cherepanov P. 2010. Retroviral intasome assembly and inhibition of DNA strand transfer. Nature 464: 232-236.

60. Ballandras-Colas A, Maskell DP, Serrao E, Locke J, Swuec P, Jónsson SR, et al. 2017. A supramolecular assembly mediates lentiviral DNA integration. Science 355: 93-95.

61. Roberts VA. 2015. C-terminal domain of integrase binds between the two active sites. J. Chem. Theory Comput. 11:4500-4511.

62. Serrao E, Ballandras-Colas A, Cherepanov P, Maertens GN, Engelman AN. 2015. Key determinants of target DNA recognition by retroviral intasomes. Retrovirology 12: 39

63. Bosserman MA, O'Quinn DF, Wong I. 2007. Loop202-208 in avian sarcoma virus integrase mediates tetramer assembly and processing activity. Biochemistry 46: 11231-11239.

64. Hare S, Di Nunzio F, Labeja A, Wang J, Engelman A, Cherepanov P. 2009. Structural basis for functional tetramerization of lentiviral integrase. PLoS Pathog. 5: e1000515.

65. Heuer TS, Brown PO. 1998. Photo-cross-linking studies suggest a model for the architecture of an active human immunodeficiency virus type 1 integrase-DNA complex. Biochemistry 37: 6667-6678.

66. Cherepanov P, Maertens G, Proost P, Devreese B, Van Beeumen J, Engelborghs Y, et al. 2003. HIV-1 integrase forms stable tetramers and associates with LEDGF/p75 protein in human cells. J. Biol. Chem. 278: 372-381.

67. Hare S, Maertens GN, Cherepanov P. 2012. 3'-Processing and strand transfer catalysed by retroviral integrase in crystallo. EMBO J. 31: 3020-3028.

68. Yin Z, Lapkouski M, Yang W, Craigie R. 2012. Assembly of prototype foamy virus strand transfer complexes on product DNA bypassing catalysis of integration. Protein Sci. 21: 1849-1857.

69. Mackler RM, Lopez Jr MA, Yoder KE. 2018. Assembly and purification of prototype foamy virus intasomes. J. Vis. Exp. $133:$ e57453.

70. Bushman F, Lewinski M, Ciuffi A, Barr S, Leipzig J, Hannenhalli S, et al. 2005. Genome-wide analysis of retroviral DNA integration. Nat. Rev. Microbiol. 3: 848-858.

71. Wu X, Li Y, Crise B, Burgess SM, Munroe DJ. 2005. Weak palindromic consensus sequences are a common feature found at the integration target sites of many retroviruses. J. Virol. 79: 5211-5214.

72. Shun MC, Raghavendra NK, Vandegraaff N, Daigle JE, Hughes S, Kellam P, et al. 2007. LEDGF/p75 functions downstream from preintegration complex formation to effect gene-specific HIV-1 integration. Genes Dev. 21: 1767-1778.

73. Holman AG, Coffin JM. 2005. Symmetrical base preferences surrounding HIV-1, avian sarcoma/leukosis virus, and murine leukemia virus integration sites. Proc. Natl. Acad. Sci. USA 102: 6103-6107.

74. Schröder AR, Shinn P, Chen H, Berry C, Ecker JR, Bushman F. 2002. HIV-1 integration in the human genome favors active genes and local hotspots. Cell 110: 521-529.

75. Crise B, Li Y, Yuan C, Morcock DR, Whitby D, Munroe DJ, et al. 2005. Simian immunodeficiency virus integration preference is similar to that of human immunodeficiency virus type 1. J. Virol. 79: 12199-12204.

76. MacNeil A, Sankalé JL, Meloni ST, Sarr AD, Mboup S, Kanki P. 2006. Genomic sites of human immunodeficiency virus type 2 (HIV2) integration: similarities to HIV-1 in vitro and possible differences in vivo. J. Virol. 80: 7316-7321.

77. Hacker CV, Vink CA, Wardell TW, Lee S, Treasure P, Kingsman SM, et al. 2006. The integration profile of EIAV-based vectors. Mol. Ther. 14: 536-545. 
78. Kang Y, Moressi CJ, Scheetz TE, Xie L, Tran DT, Casavant TL, et al. 2006. Integration site choice of a feline immunodeficiency virus vector. J. Virol. 80: 8820-8823.

79. Mitchell RS, Beitzel BF, Schroder AR, Shinn P, Chen H, Berry CC, et al. 2004. Retroviral DNA integration: ASLV, HIV, and MLV show distinct target site preferences. PLoS Biol. 2: e234

80. Nowrouzi A, Dittrich M, Klanke C, Heinkelein M, Rammling M, Dandekar T, et al. 2006. Genome-wide mapping of foamy virus vector integrations into a human cell line. J. Gen. Virol. 87: 1339-1347.

81. Trobridge GD, Miller DG, Jacobs MA, Allen JM, Kiem HP, Kaul R, et al. 2006. Foamy virus vector integration sites in normal human cells. Proc. Natl. Acad. Sci. USA 103: 1498-1503.

82. Stevens SW, Griffith JD. 1996. Sequence analysis of the human DNA flanking sites of human immunodeficiency virus type 1 integration. J. Virol. 70: 6459-6462.

83. Derse D, Crise B, Li Y, Princler G, Lum N, Stewart C, et al. 2007. Human T-cell leukemia virus type 1 integration target sites in the human genome: comparison with those of other retroviruses. J. Virol. 81: 6731-6741.

84. Berry C, Hannenhalli S, Leipzig J, Bushman FD. 2006. Selection of target sites for mobile DNA integration in the human genome. PLoS Comput. Biol. 2: e157.

85. Lee HS, Kang SY, Shin CG. 2005. Characterization of the functional domains of human foamy virus integrase using chimeric integrases. Mol. Cells 19: 246-255.

86. Kim J, Lee GE, Löchelt M, Shin CG. 2018. Integrase C-terminal residues determine the efficiency of feline foamy viral DNA integration. Virology 514: 50-56.

87. Pahl A, Flügel RM. 1995. Characterization of the human spuma retrovirus integrase by site-directed mutagenesis, by complementation analysis, and by swapping the zinc finger domain of HIV-1. J. Biol. Chem. 270: 2957-2966.

88. Heinkelein M, Leurs C, Rammling M, Peters K. Hanenberg H, Rethwilm A. 2002. Pregenomic RNA is required for efficient incorporation of Pol polyprotein into foamy virus capsids. J. Virol. 76: 10069-10073.

89. Tobaly-Tapiero J, Bittoun P, Lehmann-Che J, Delelis O, Giron ML, de Thé H, et al. 2008. Chromatin tethering of incoming foamy virus by the structural Gag protein. Traffic 9: 1717-1727.

90. Lo YT, Tian T, Nadeau PE, Park J, Mergia A. 2010. The foamy virus genome remains unintegrated in the nuclei of $\mathrm{G}_{1} / \mathrm{S}$ phase-arrested cells, and integrase is critical for preintegration complex transport into the nucleus. J. Virol. 84: 2832-2842.

91. Müllers E, Stirnnagel K, Kaulfuss S, Lindemann D. 2011. Prototype foamy virus (PFV) Gag nuclear localization: a novel pathway among retroviruses. J. Virol. 85: 9276-9285.

92. An DG, Hyun U, Shin CG. 2008. Characterization of nuclear localization signals of the prototype foamy virus integrase. J. Gen. Virol. 89: $1680-1684$

93. Hossain MA, Ali MK, Shin CG. 2014. Nuclear localization signals in prototype foamy viral integrase for successive infection and replication in dividing cells. Mol. Cells 37: 140-148.

94. Hamid FB, Kim J, Shin CG. 2017. Characterization of prototype foamy virus infectivity in transportin 3 knockdown human $293 \mathrm{~T}$ cell line. J. Microbiol. Biotechnol. 27: 380-387.

95. Ali MK, Kim J, Hamid FB, Shin CG. 2015. Knockdown of the host cellular protein transportin 3 attenuates prototype foamy virus infection. Biosci. Biotechnol. Biochem. 79: 943-951.

96. Bodem J. 2011. Regulation of foamy viral transcription and RNA export. Adv. Virus Res. 81: 1-31.

97. Yu SF, Baldwin DN, Gwynn SR, Yendapalli S, Linial ML. 1996. Human foamy virus replication: a pathway distinct from that of retroviruses and hepadnaviruses. Science 271: 1579-1582.

98. Bodem J, Löchelt M, Winkler I, Flower RP, Delius H, Flügel RM. 1996. Characterization of the spliced pol transcript of feline foamy virus: the splice acceptor site of the pol transcript is located in gag of foamy viruses. J. Virol. 70: 9024-9027.

99. Löchelt M, Muranyi W, Flügel RM. 1993. Human foamy virus genome possesses an internal, Bel-1-dependent and functional promoter. Proc. Natl. Acad. Sci. USA 90: 7317-7321.

100. Löchelt M, Romen F, Bastone P, Muckenfuss H, Kirchner N, Kim YB, et al. 2005. The antiretroviral activity of APOBEC3 is inhibited by the foamy virus accessory Bet protein. Proc. Natl. Acad. Sci. USA 102: 7982-7987.

101. Löchelt M. 2003. Foamy virus transactivation and gene expression, pp. 27-61. In Rethwilm A (ed.), Foamy Viruses. Springer, New York, NY.

102. Peters K, Barg N, Gärtner K, Rethwilm A. 2008. Complex effects of foamy virus central purine-rich regions on viral replication. Virology 373: 51-60.

103. Hartl MJ, Bodem J, Jochheim F, Rethwilm A, Rösch P, Wöhrl BM. 2011. Regulation of foamy virus protease activity by viral RNA: a novel and unique mechanism among retroviruses. J. Virol. 85: 4462-4469.

104. Moschall R, Denk S, Erkelenz S, Schenk C, Schaal H, Boden J. 2017. A purine-rich element in foamy virus pol regulates env splicing and gag/pol expression. Retrovirology 14: 10 .

105. Lee EG, Roy J, Jackson D, Clark P, Boyer PL, Hughes SH, et al. 2011. Foamy retrovirus integrase contains a Pol dimerization domain required for protease activation. J. Virol. 85: 1655-1661.

106. Spannaus R, Hartl MJ, Wöhrl BM, Rethwilm A, Bodem J. 2012. The prototype foamy virus protease is active independently of the integrase domain. Retrovirology 9: 41.

107. Pahl A, Flügel RM. 1993. Endonucleolytic cleavages and DNA-joining activities of the integration protein of human foamy virus. J. Virol. 67: 5426-5434.

108. Sinha S, Grandgenett DP. 2005. Recombinant human immunodeficiency virus type 1 integrase exhibits a capacity for full-site integration in vitro that is comparable to that of purified preintegration complexes from virus-infected cells. J. Virol. 79: 8208-8216.

109. Li M, Craigie R. 2005. Processing of viral DNA ends channels the HIV-1 integration reaction to concerted integration. J. Biol. Chem. 280: 29334-29339.

110. Knyazhanskaya ES, Smolov MA, Kondrashina OV, Gottikh MB. 2009. Relative comparison of catalytic characteristics of human foamy virus and HIV-1 integrases. Acta Naturae 1: 78-80.

111. Smolov M, Gottikh M, Tashlitskii V, Korolev S, Demidyuk I, Brochon JC, et al. 2006. Kinetic study of the HIV-1 DNA 3-end processing. FEBS J. 273: 1137-1151.

112. Kang SY, Ahn DG, Lee C, Lee YS, Shin CG. 2008. Functional nucleotides of U5 LTR determining substrate specificity of prototype foamy virus integrase. J. Microbiol. Biotechnol. 18: 1044-1049.

113. Oh YT, Shin CG. 1999. Comparison of enzymatic activities of the HIV-1 and HFV integrases to their U5 LTR substrates. IUBMB Life 47: 621-629.

114. Aiyer S, Rossi P, Malani N, Schneider WM, Chandar A, Bushman FD, et al. 2015. Structural and sequencing analysis of local target DNA recognition by MLV integrase. Nucleic Acids Res. 43: 5647-5663.

115. Mackler RM, Lopez MA, Osterhage MJ, Yoder KE. 2018. Prototype foamy virus integrase is promiscuous for target choice. Biochem. Biophys. Res. Commun. 503: 1241-1246.

116. Cavazza A, Moiani A, Mavilio F. 2013. Mechanisms of retroviral integration and mutagenesis. Hum. Gene Ther. 24: 119-131.

117. Trobridge G, Josephson N, Vassilopoulos G, Mac J, Russell DW. 2002. Improved foamy virus vectors with minimal viral sequences. Mol. Ther. 6: 321-328 
118. Heinkelein M, Dressler M, Jármy G, Rammling M, Imrich H, Thurow J, et al. 2002. Improved primate foamy virus vectors and packaging constructs. J. Virol. 76: 3774-3783.

119. Wiktorowicz T, Peters K, Armbruster N, Steinert AF, Rethwilm A. 2009. Generation of an improved foamy virus vector by dissection of cis-acting sequences. J. Gen. Virol. 90: 481-487.

120. Müllers E, Uhlig T, Stirnnagel K, Fiebig U, Zentgraf H, Lindemann D. 2011. Novel functions of prototype foamy virus Gag glycinearginine-rich boxes in reverse transcription and particle morphogenesis. J. Virol. 85: 1452-1463.

121. Bauer Jr TR, Allen JM, Hai M, Tuschong LM, Khan IF, Olson EM, et al. 2008. Successful treatment of canine leukocyte adhesion deficiency by foamy virus vectors. Nat. Med. 14: 93-97.

122. Bauer Jr TR, Tuschong LM, Calvo KR, Shive HR, Burkholder TH, Karlsson EK, et al. 2013. Long-term follow-up of foamy viral vector-mediated gene therapy for canine leukocyte adhesion deficiency. Mol. Ther. 21: 964-972.

123. Hocum JD, Linde I, Rae DT, Collins CP, Matern LK, Trobridge GD. 2016. Retargeted foamy virus vectors integrate less frequently near proto-oncogenes. Sci. Rep. 6: 36610 .

124. Deyle DR, Li Y, Olson EM, Russell DW. 2010. Nonintegrating foamy virus vectors. J. Virol. 84: 9341-9349.

125. Nasimuzzaman M, Lynn D, Ernst R, Beuerlein M, Smith RH, Shrestha A, et al. 2016. Production and purification of high-titer foamy virus vector for the treatment of leukocyte adhesion deficiency. Mol. Ther. Methods Clin. Dev. 3: 16004

126. Merten OW, Hebben M, Bovolenta C. 2016. Production of lentiviral vectors. Mol. Ther. Methods Clin. Dev. 3: 16017.

127. Sweeney NP, Meng J, Patterson H, Morgan JE, McClure M. 2017. Delivery of large transgene cassettes by foamy virus vector. Sci. Rep. 7: 8085.

128. Sweeney NP, Regan C, Liu J, Galleu A, Dazzi F, Lindemann D, et al. 2016. Rapid and efficient stable gene transfer to mesenchymal stromal cells using a modified foamy virus vector. Mol. Ther. 24: 1227-1236. 